\title{
Gender Effects of BDSM Participation on Self-Reported Psychological Distress Levels
}

\author{
Thea Alvarado \\ Pasadena Community College (USA) \\ tsweoalvarado@gmail.com \\ Emily E. Prior \\ Center for Positive Sexuality (USA) \\ Jeremy N. Thomas \\ Center for Positive Sexuality (USA) \\ Idaho State University (USA) \\ D J Williams \\ Center for Positive Sexuality (USA) \\ Idaho State University (USA)
}

\section{Introduction}

Previous research shows inconclusive evidence of differences between genders related to stress. While some research indicates that gender is a related variable (Carrillo et al., 2001; Lepore, Ragan, \& Jones, 2000), other research has been unable to determine this clearly (Kudielka, Buske-Kirschbaum, Hellhammer, \& Kirschbaum, 2004; Labouvie-Vief, Lumley, Jain, \& Heinze, 2003). It is also unclear as to whether stress coping abilities may differ by gender.

When looking at gender as a social construct, there may be differences in how men and women perceive and cope with stress based on how they, as individuals, were likely taught to react. It seems clear that even in modern Western society, men and women are still socialized based on their perceived, inherent differences. Since we cannot easily remove gendered socialization from the equation, we find ourselves continuing to support a binary reaction to stress along male-female lines.

Although the literature is conflicted regarding the relationship between stress and gender, there seems to be support for women experiencing more stress than men (Almeida \& Kessler, 1998; McDonough \& Walters, 2001) or at least perceiving certain situations as more stressful than men perceive those same situations (Miller \& Kirsch, 1987; Ptacek, Smith, \& Zanas, 1992). Research also shows that men and women perceive different things as stressful (work versus family, for instance) or perceive the same thing as stressful for different reasons based on their presumed gender roles such as co-worker relations versus a need to achieve higher status at work (Matthews, Hertzman, Ostry, \& Power, 1998).

Although often associated, there is a difference between perceived stress (psychological) and actual physiological stress. When examining cortisol levels, it seems possible that gender differences may be more dependent on the type of stressor (Stroud, Salovey, \& Epel, 2002). However, even these studies have reported mixed findings, and it is not clear whether women 
actually experience more stress than men, whether women and men perceive and process stress differently, or if gender is really a factor at all.

Another issue that is not actively addressed in the stress literature are genders outside of the binary. Transgender, genderfluid, and other non-cis-gendered identities are left out of the conversation completely, or when addressed, the stress discussed is primarily focused on the person's experience of gender identity and not related to any other stress the person may be experiencing (e.g., Schrager \& Meyer, 2016; Hoy-Ellis \& Frederiksen-Goldsen, 2017).

An interesting element that has surfaced in the literature, however, is the issue of power, and how it might act as a mediator in stress coping processes across genders (Matud, 2004). While studies have mostly focused on women's lack of access to power via sexism, only a few studies have looked at women's access to power via BDSM interactions. One such study suggests that women who engage in BDSM, regardless of role (top or bottom), feel empowered based on the exchange within the relationship dynamic (Prior, 2013). It is likely that feeling empowered may lead to lower perceived stress levels.

Research suggests that because of the complexity of BDSM and its connections to other important aspects of self, BDSM likely is experienced differently according to gender identity (Breslow, et al., 1985; Prior, 2013). This may play out in terms of psychological stress appraisal. In a nationally representative sample $(\mathrm{N}=19,307)$, Richters and colleagues (2008) found that women who participate in BDSM were more likely to report experiencing higher overall psychological distress than non-BDSM females, though this finding was not statistically significant. However, Richters and colleagues (2008) found the opposite for males - those who participate in BDSM were statistically more likely $(p<=.01)$ to report reduced overall psychological distress compared to males who do not engage in such behaviors.

BDSM may be understood as a particular set of desired leisure activities that are often erotically motivated and produce psychological benefits (Hebert \& Weaver, 2015; Prior \& Williams, 2015; Taylor \& Ussher, 2001; Williams, Prior, Alvarado, Thomas, \& Christensen 2016). As leisure, BDSM may be more or less casual (playful, spontaneous, requires little skill) or serious (requires skill, effort, perseverance, and is associated with a salient identity), depending on the people and activities involved (Newmahr, 2011; Prior \& Williams, 2015; Williams, 2006; Williams et al., 2016). Regarding degree of BDSM involvement, some at the far end of the serious leisure continuum may understand BDSM as an alternative sexual orientation (Gemberling, Cramer, \& Miller, 2015).

Although a common property of a diverse range of leisure behaviors is stress reduction, there is often a disconnect between physiological and psychological stress with respect to intense, adventurous, physically-active experiences, such as rock-climbing or kayaking. In a recent study, 91\% of BDSM participants ( $\mathrm{N}=935)$ reported their BDSM activities were, overall, associated with reduced psychological stress. At the same time, Sagarin and colleagues (2015) found increases in cortisol levels of BDSM bottoms before and during BDSM play, indicative of physiological stress. Sagarin and colleagues (2015) also found that, similar to bottoms, BDSM tops reported low psychological stress during BDSM activities; however, tops did not show increases in cortisol levels during BDSM play. Despite potential differences in actual 
physiological stress, BDSM participants across roles likely experience reduced psychological stress due to personally meaningful leisure experiences wherein there is an optimal balance of skill and challenge, or flow (see Csikszentmihalyi, 1997) and possibly altered states of consciousness (i.e., subspace) (Pitagora, 2017; Sagarin, et al., 2015).

In light of the above background, the present study sought to determine if there is a statistical difference between male and female BDSM participants regarding their perceptions of BDSM participation being associated with lower psychological stress levels.

\section{Methods}

As part of a larger study on BDSM as potential leisure experience (Williams et al., 2016), adult participants ( $\mathrm{N}=935)$ were asked whether they associated their BDSM participation with relaxation or reduced stress. Genders of participants were self-identified and could be chosen from a list and/or written in using their own words. Both cisgender (in this case, self-identified males and females and/or participants who specifically used "cisgender" as a response) and transgender (participants using other terms for their gender identity, including but not limited to, MTF, FTM, transgender, gender fluid, etc.) individuals’ responses were compared relative to perceived stress reduction.

\section{Results}

A chi-square test was used to analyze whether there was a statistically significant difference in how self-identified males and females reported whether or not their BDSM participation was associated with stress reduction or relaxation. Survey response options ranged on a Likert scale from "not at all” to "nearly always/always." There was a statistically significant gender difference at the $p<=.01$ level. Notably, 70.8\% of females responded that BDSM helps them relax or feel less stress "nearly always or always," compared to 55.4\% of males. Cisgender and transgender participants' responses to BDSM participation and potential stress reduction were also compared, but this difference was not statistically significant.

\section{Discussion}

It seems interesting that significantly more female participants would find BDSM activities more relaxing or stress relieving than male participants, especially given that $57 \%$ of women identified as submissive compared to $9 \%$ identifying as dominant. Although one would think that a submissive female would experience higher levels of stress given the connection to women being more powerless in society, this result indicates that within a BDSM context, having the autonomy to exchange power with another person may actually reduce one's stress.

Although not as high a percentage, a significant number of men also felt that their BDSM activities helped them relax or feel less stress. Of this group, $42 \%$ of men identified as dominant and 25\% identified as submissive. This might indicate that for men, stress reduction during BDSM activities is not as related to BDSM identity as it may be to other factors, like the activity itself, partners, or setting. Clearly, more research is needed to explore how self-reported 
psychological distress levels are related to gender and potentially interact with BDSM activities such at topping and bottoming and BDSM identities such as dominants and submissives.

\section{References}

Almeida, D. M., \& Kessler, R. C. (1998). Everyday stressors and gender differences in daily distress. Journal of Personality and Social Psychology, 75, 670-680.

Breslow, N., Evans, L., \& Langley, J. (1985). On the prevalence and roles of females in the sadomasochistic subculture: Report of an empirical study. Archives of Sexual Behavior, 14, 303-317.

Carrillo, E., Moya-Albiol L., Gonzalez-Bono, E., Salavador, A., Ricarte, J., \& Gomez-Amor, J., (2001). Gender differences in cardiovascular and electrodermal response to public speaking task: The role of anxiety and mood states. International Journal of Psychophysiology, 42, 253-264.

Csikszentmihalyi, M. (1997). Finding flow: The psychology of engagement with everyday life. New York: Basic Books.

Gemberling, T. M., Cramer, R., \& Miller, R. S. (2015). BDSM as sexual orientation: A comparison to lesbian, gay, and bisexual sexuality. Journal of Positive Sexuality, 1, 56-62.

Hebert, A., \& Weaver, A. (2015). Perks, problems, and the people who play: A qualitative exploration of dominant and submissive BDSM roles. Canadian Journal of Human Sexuality, 24, 49-62.

Hoy-Ellis, C., \& Fredriksen-Goldsen, K. (2017). Depression Among Transgender Older Adults: General and Minority Stress. American Journal of Community Psychology, 59(3-4), 295-305.

Kudielka, B.M., Buske-Kirschbaum, A., Hellhammer, D. H., \& Kirschbaum, C. (2004). Differential heart rate reactivity and recovery after psychosocial stress (TSST) in healthy children, younger adults, and elderly adults: the impact of age and gender. International Journal of Behavioral Medicine, 11, 116-121.

Labouvie-Vief, G., Lumley, M. A., Jain, E., \& Heinze, H. (2003). Age and gender differences in cardiac reactivity and subjective emotional responses to emotional autobiographical memories. Emotion, 3, 115-126.
Lepore, S. J., Ragan, J. D., \& Jones, S. (2000). Talking facilitates cognitive-emotional processes of adaptation to an acute stressor. Journal of Personality and Social Psychology, 78, 499-508.

Matthews, S., Hertzman, C., Ostry, A., \& Power, C. (1998). Gender, work roles and psychosocial work characteristics as determinants of health. Social Science and Medicine, 46, 1417-1424.

Matud, M. P. (2004). Gender differences in stress and coping styles. Personality and Individual Differences, 37, 1401-1415.

McDonough, P., \& Walters, W. (2001). Gender and health: reassessing patterns and explanations. Social Science \& Medicine, 52, 547-559.

Miller, S. M., \& Kirsch, N. (1987). Sex differences in cognitive coping with stress. In R. C. Barnett, L. Biener, \& G. K. Baruch (Eds.), Gender \& Stress (pp. 278-307). New York: The Free Press.

Pitagora, D. (2017). No pain, no gain? Therapeutic and relational benefits of subspace in BDSM contexts. Journal of Positive Sexuality, 3, 44-54.

Prior, E. E. (2013). Women's perspectives of BDSM power exchange. Electronic Journal of Human Sexuality, Volume 16.

Prior, E. E., \& Williams, D J. (2015). Does BDSM power exchange among women reflect casual leisure? An exploratory qualitative study. Journal of Positive Sexuality, 1, 12 15.

Ptacek, J. T., Smith, R. E., \& Zanas, J. (1992). Gender, appraisal, and coping: A longitudinal analysis. Journal of Personality, 60, 747-770.

Richters, J., de Visser, R. O., Rissel, C. E., Grulich, A. E., \& Smith, A. M. A. (2008). Demographic and psychosocial features of participants in bondage and discipline, "sadomasochism" or dominance and submission (BDSM): Data from a national survey. Journal of Sexual Medicine, 5, 1660-1668. 
Sagarin, B. J., Lee, E. M., \& Klement, K. R. (2015). Sadomasochism without sex: Exploring the parallels between BDSM and extreme rituals. Journal of Positive Sexuality, 1, 5055.

Schrager, S., \& Meyer, I. (2016). Current and Future Directions in Lesbian, Gay, Bisexual, and Transgender (LGBT) Youth Minority Stress and Health Research. International Journal of Psychology, 51(S1), 611.

Stroud, L. R., Salovey, P. \& Epel, E. S. (2002). Sex differences in stress responses: Social rejection versus achievement stress. Biological Psychiatry, 52, 318-327.
Taylor, G. W., \& Ussher, J., M. (2001). Making sense of S\&M: A discourse analytic account. Sexualities, 4(3), 293-314.

Williams, D J (2006). Different (painful!) strokes for different folks: A general overview of sadomasochism (SM) and its diversity. Sexual Addiction \& Compulsivity, 13, 333346.

Williams, D J, Prior, E. E., Alvarado, T., Thomas, J. N., \& Christensen, M. C. (2016). Is bondage and discipline, dominance and submission, and sadomasochism recreational leisure? A descriptive exploratory investigation. Journal of Sexual Medicine, 13, 1091-1094. 